\title{
Mucormicosis endobronquial, una presentación atípica
}

\author{
Endobronchial mucormycosis, a rare presentation
}

\section{CASE REPORT}

Mucormycosis is a rare, opportunistic and life-threatening fungal infection that mostly affects immunocompromised patients such as diabetic and transplant patients.

It is usually caused by fungi of the order Mucorales. Rhizopus and Mucor are the most common responsible microorganisms. It's a systemic pathology that manifests in the form of different clinical syndromes with rhino-cerebral, pulmonary, gastrointestinal, central nervous system, subcutaneous involvement and the disseminated form.

We present the case of a 50-year-old patient with type 2 diabetes with poor metabolic control (22\% HbA1c) presented to the Emergency Department with disorientation, adynamia, drowsiness and fever with two days of evolution. Upon observation, the patient was polypneic (respiratory rate $23 \mathrm{cpm}$ ) and with depressed state of consciousness (GCS 11). Arterial blood gas analysis revealed severe metabolic acidemia (pH 6.9 and HCO3 3,1 mmol/L). Blood analysis revealed leukocytosis (28.000 cells/uL) with neutrophilia (18.000 cells/ uL), CRP $17 \mathrm{mg} / \mathrm{dL}$, blood glucose $664 \mathrm{mg} / \mathrm{dL}$, ketonemia $4.2 \mathrm{mg} / \mathrm{dL}$ and creatinine of $1.44 \mathrm{mg} / \mathrm{dL}$. Influenza B test turned out to be positive. Chest radiography demonstrated consolidation in the lower third of the left pulmonary field. The diagnosis of diabetic ketoacidosis was admitted in a patient with Influenza B and bacterial overinfection. The patient started insulin therapy with glycemic control and resolution of ketoacidosis.

He completed therapy with oseltamivir, ceftriaxone and clarithromycin, however, the patient maintained the fever and elevated inflammatory parameters. Blood cultures turned out negative. Chest CT revealed consolidation with air bronchogram in the left lower lobe and mild left pleural effusion. In this context, a bronchofibroscopy was performed, which revealed white plaques adhering to the mucosa of the left main bronchus and left upper and lower lobar bronchi suggestive of fungal infection. Multiple endobronchial biopsies were performed and revealed multiple large septate hyphae with necrosis and angioinvasion suggestive of mucormycosis.

The patient stanted anti-fungal therapy with isovuconazole (200mg tid in the first 48h and then 200mg once daily) with significante clinical and ragiological improvement. He was discharged with the indication to maintain antifungal therapy for 6 weeks and repeat chest CT after completing therapy.
Figure 1. Bronchoscopy endoscopic image revealing white plaques adhering to the mucosa of the left main bronchus, left lower and superior bronchi suggestive of fungal infection. A forceps biopsy being performed.

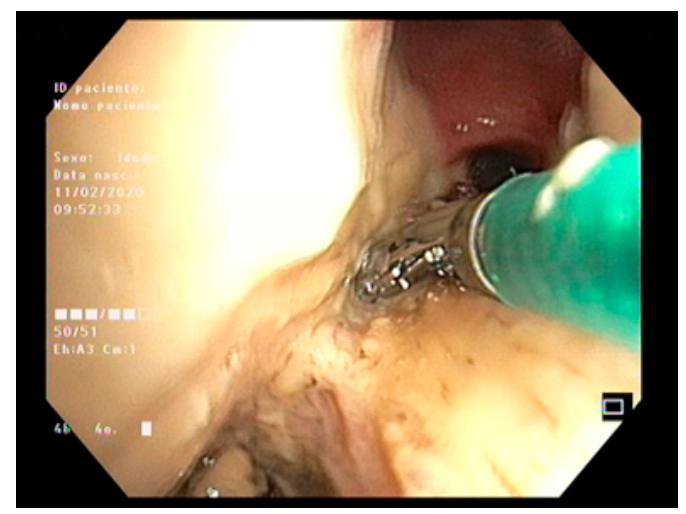

Figure 2. Bronchoscopy endoscopic image revealing white plaques adhering to the mucosa of the left main bronchus, left lower and superior bronchi suggestive of fungal infection.

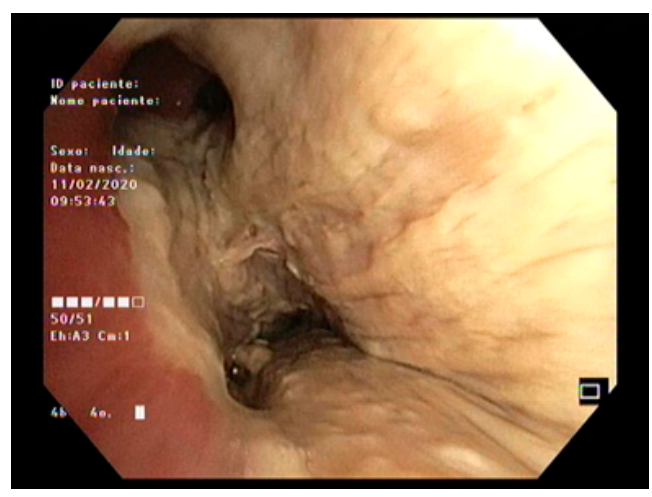

\section{REFERENCES}

1. Viterbo $S$, Fasolis $M$, Garzino-Demo $P$, Griffa $A$, Boffano $P$, laquinta $C$, et al. Management and outcomes of three cases of rhinocerebral mucormycosis. Oral Surg Oral Med Oral Pathol Oral Radiol Endod. 2011;112:e69-74.

2. Benoit $P$, Alexandre $A$, et al., Recent advances in the understanding and management of mucormycosis, review article, 2018

3. Venugopal J, Vijaya M, Santhakumar S, et al., Mucormycosis: an unusual masquerador of an endobronchieal tumour, Respirology Case Reports, 2019

4. Roden MM, Zaoutis TE, Buchanan WL, Knudsen TA, Sarkisova TA, Schaufele RL, Sein M, Sein T, Chiou CC, Chu JH, Kontoyiannis DP, Walsh TJ. Epidemiology and outcome of zygomycosis: a review of 929 reported cases. Clin Infect Dis 2005;41:634-653

5. Spellberg B, Ibrahim A. Recent Advances in the Treatment of Mucormycosis. Current Infectious Disease Reports. 2010; 12: 423-429.

Palabras clave: mucormicosis, infección fúngica, diabetes. Keywords: mucormycosis, fungal infection, diabetes.

André Fabiano, Maria Inês Ferreira

Serviço de Pneumologia. Hospital Professor Doutor Fernando Fonseca. Portugal

Correspondencia: afabiano27@gmail.com

Cómo citar este artículo: Fabiano A, Ferreira Ml

Mucormicosis endobronquial, una presentación atípica. Galicia Clin 2021; 82-2: 121

Recibido: 7/4/2020; Aceptado: 20/1/2021 // https://doi.org/10.22546/61/2285 